University of New Orleans

ScholarWorks@UNO

$11-7-2010$

\title{
Synthesis of mild-hard AAO templates for studying magnetic interactions between metal nanowires
}

Jin-Hee Lim

University of New Orleans

Aurelian Rotaru

Seong-Gi Min

University of New Orleans

Leszek Malkinski

University of New Orleans

John B. Wiley

University of New Orleans

Follow this and additional works at: https://scholarworks.uno.edu/phys_facpubs

Part of the Materials Science and Engineering Commons, Nanoscience and Nanotechnology Commons, and the Physics Commons

\section{Recommended Citation}

J. Mater. Chem. 209246 (2010)

This Article is brought to you for free and open access by the Department of Physics at ScholarWorks@UNO. It has been accepted for inclusion in Physics Faculty Publications by an authorized administrator of ScholarWorks@UNO. For more information, please contact scholarworks@uno.edu. 


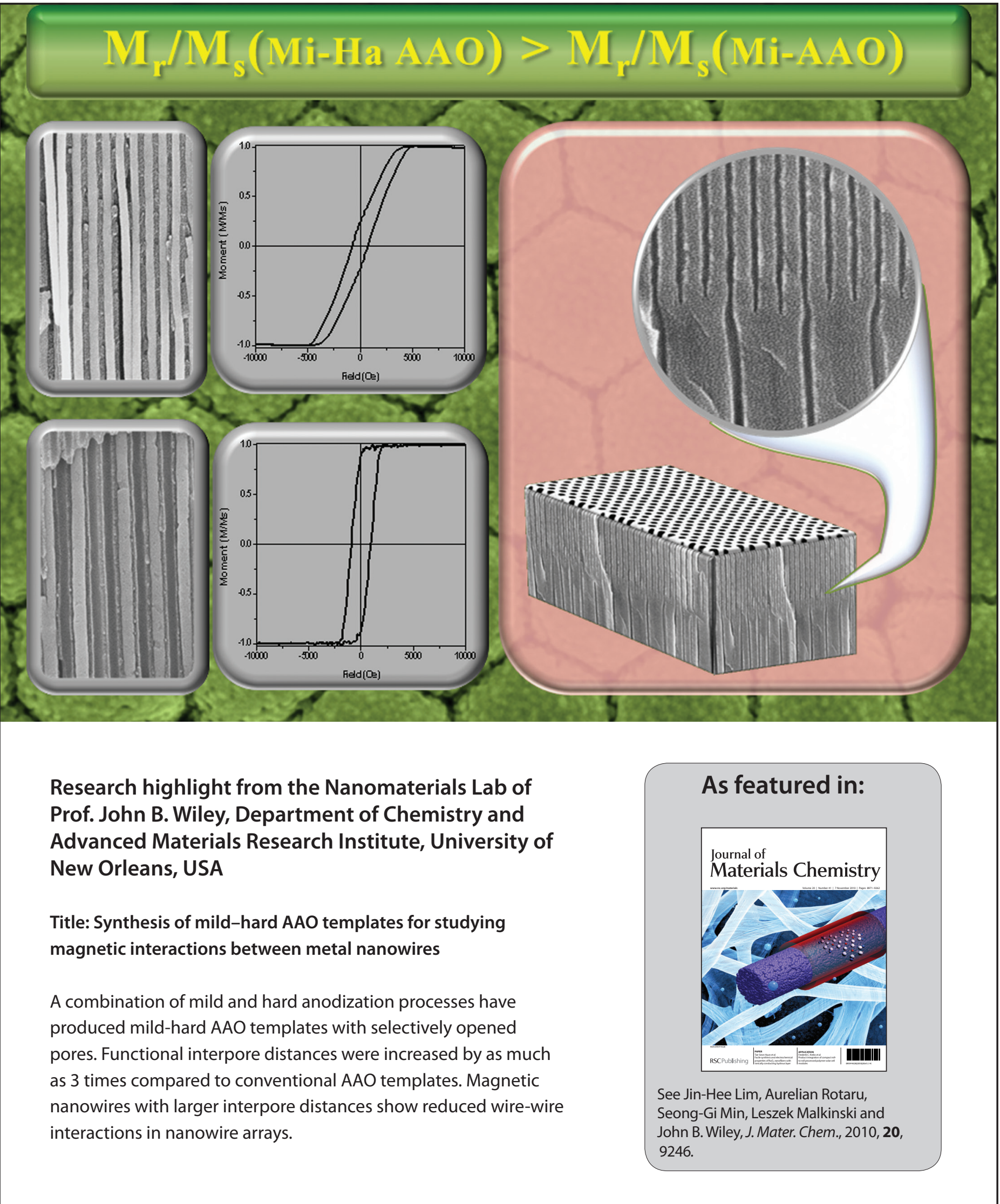




\title{
Synthesis of mild-hard AAO templates for studying magnetic interactions between metal nanowires $\dagger$
}

\author{
Jin-Hee Lim, ${ }^{a}$ Aurelian Rotaru, ${ }^{b}$ Seong-Gi Min, ${ }^{b}$ Leszek Malkinski ${ }^{b}$ and John B. Wiley ${ }^{* a}$ \\ Received 8th May 2010, Accepted 29th July 2010 \\ DOI: 10.1039/c0jm01365j
}

The sequential application of mild and hard anodization techniques in the fabrication of porous alumina membranes allows one to decrease the number of continuous pores in anodized aluminium oxide (AAO) templates. Initially, standard mild anodization techniques were used to create porous templates with $100 \mathrm{~nm}$ interpore distances and $70 \mathrm{~nm}$ pore diameters. Hard anodization treatment on the same membrane then produced interpore distances of about $265 \mathrm{~nm}$ with diameters of $110 \mathrm{~nm}$. At the interface between the two anodization steps, many of the mild-side pores were terminated to create a mild-hard membrane (Mi-Ha $\mathrm{AAO})$ where the functional interpore distances were 200-300 nm. Growth (electrodeposition) of nickel and cobalt nanowires in the various pore structures of the mild and hard sides of the Mi-Ha AAO templates allows one to probe magnetic interactions between nanowires and compares them to wires grown in standard mild templates (Mi-AAO). The magnetic properties of nanowires in Mi-Ha AAO and Mi-AAO showed distinct differences in the squareness of hysteresis loops and coercivity both as a function of pore structure and magnetic component. In general, the squareness of the hysteresis loops increased with aspect ratio and greater interpore distance. Coercivity also showed an increase with aspect ratio, but varied differently with interpore distance for $\mathrm{Ni}$ and $\mathrm{Co}$. These various magnetic behaviors are discussed with respect to crystalline structure, morphology, and interactions of adjacent sets of nanowires.

\section{Introduction}

Since Masuda and Fukuda reported the two-step anodization process for the synthesis of AAO (anodized aluminium oxide) templates with highly ordered hexagonal nanopores, ${ }^{1}$ many researchers have studied these materials. Conventional AAO templates are typically synthesized under the well-known 'mild' anodizing conditions, which have a slow growth rate (below 10 $\left.\mu \mathrm{m} \mathrm{h}^{-1}\right)$. Variations in reaction conditions allow one to control pore sizes and interpore distances. Examples include (1) $0.3 \mathrm{M}$ $\mathrm{H}_{2} \mathrm{SO}_{4}$ at $25 \mathrm{~V}$ for $20 \mathrm{~nm}$ pore sizes with $60 \mathrm{~nm}$ interpore distances, (2) $0.3 \mathrm{M} \mathrm{H}_{2} \mathrm{C}_{2} \mathrm{O}_{4}$ at $40 \mathrm{~V}$ for $40 \mathrm{~nm}$ pore sizes with $100 \mathrm{~nm}$ interpore distances, and (3) $0.1 \mathrm{M} \mathrm{H}_{3} \mathrm{PO}_{4}$ at $195 \mathrm{~V}$ for $400 \mathrm{~nm}$ pore sizes with $500 \mathrm{~nm}$ interpore distances. ${ }^{2}$ Mild anodization methods have several limitations such as long processing times, limited domain sizes, and fixed interpore distances. In recent years, researchers have expanded on these techniques so as to prepare a variety of structures including AAO membranes with Y-branching, ${ }^{3,4}$ six-membered rings, ${ }^{5}$ and triangular and rectangular shapes, ${ }^{6}$ by altering the anodization conditions or by a preprocessing of the anode via lithography or an imprinting method (a summary of these results is presented in ESI $\dagger$,

\footnotetext{
${ }^{a}$ Department of Chemistry and Advanced Materials Research Institute, University of New Orleans, New Orleans, LA, 70148, USA. E-mail. jwiley@uno.edu; Fax: +1 (504)280-6860; Tel: +1 (504)280-6849

${ }^{b}$ Department of Physics and Advanced Materials Research Institute, University of New Orleans, New Orleans, LA, 70148, USA

$\uparrow$ Electronic supplementary information (ESI) available: Table summarizing literature on AAO fabrication and some additional TEM/SAED on nickel and cobalt nanowires. See DOI: $10.1039 / \mathrm{c} 0 \mathrm{jm} 01365 \mathrm{j}$
}

Table S1). Additionally, a 'hard' anodization process, which has a fast film growth rate $\left(50-100 \mu \mathrm{m} \mathrm{h}^{-1}\right)$ and a range of interpore distances, has been reported by several research teams to minimize the limitations in processing seen in the production of conventional AAO templates. $\mathrm{Li}$ et $a .^{7}$ fabricated AAO templates with 70-140 nm or 225-400 nm interpore distances in a $\mathrm{H}_{2} \mathrm{SO}_{4}-\mathrm{C}_{2} \mathrm{H}_{5} \mathrm{OH}$ or $\mathrm{H}_{2} \mathrm{C}_{2} \mathrm{O}_{4}-\mathrm{C}_{2} \mathrm{H}_{5} \mathrm{OH}$ solution, respectively. Lee et al. ${ }^{8,9}$ used a $\mathrm{H}_{2} \mathrm{C}_{2} \mathrm{O}_{4}$ solution in the synthesis of hard anodized AAO templates with 200-300 nm interpore distances or used a $\mathrm{H}_{2} \mathrm{SO}_{4}$ solution for synthesis of alumina nanotubes based on a pulsed technique involving a combination of mild and hard (Mi-Ha) anodization steps.

AAO templates have been widely used in the fabrication of a variety of magnetic nanowires including $\mathrm{Fe},{ }^{10} \mathrm{Co},{ }^{11} \mathrm{Ni},{ }^{12}$ $\mathrm{CoPt},{ }^{13} \mathrm{FePt},{ }^{14}$ or $\mathrm{Fe}_{3} \mathrm{O}_{4}{ }^{15}$ Interest in such systems includes potential applications in microwave electronics as filters or circulators $^{16}$ as well as in fundamental studies of perpendicular magnetic media. ${ }^{17}$ The magnetic properties of AAO-nanowire composites strongly depend not only on the length of the magnetic component, but also on the diameter, shape, and interwire distance. The total effective anisotropy field is defined as the sum of dipolar interaction, magnetocrystalline, and shape anisotropy field. ${ }^{18}$ Dipolar coupling between magnetic nanowires can greatly influence the properties of such composite systems. ${ }^{17}$ To study the dipolar interaction, several research groups focused on Ni nanowires with different aspect ratios (length/diameter) at constant interwire distances. In the case of Ni nanowires with low aspect ratios, the dipolar interactions are significant and they can cancel or overcome the shape anisotropy. ${ }^{19}$ Piraux et al. ${ }^{18}$ synthesized $\mathrm{Ni}$ nanowires in polycarbonate and commercial alumina templates with different porosities and showed that 
enhanced porosity (smaller interwire distance) increased the dipolar interaction between nanowires. Although dipolar coupling has been investigated in a number of systems, these studies have not involved the variation of interpore distance with sets of wires with constant diameter and length. Therefore, the modification of interwire distance using AAO templates with well-ordered structures offers an important opportunity to explore these effects.

Herein we describe an alternative method for producing large interpore distances by sequential application of both mild and hard anodizing processes. This approach provides stable anodizing conditions for the fabrication of large area porous templates with selectively opened pores. Magnetic nanowire arrays produced from these templates demonstrate properties different than those synthesized in traditional mild templates. It should be noted that we recently described some initial results on iron nanowires elsewhere. ${ }^{20}$

\section{Experimental}

\section{Preparation of conventional mild AAO and mild-hard AAO templates}

Conventional mild AAO templates (Mi-AAO) were synthesized by using a two-step anodization process in oxalic acid solution. ${ }^{21}$ High purity Al $\left(99.999 \%, 0.25 \mathrm{~mm}\right.$ thickness, $\left.1 \times 2.5 \mathrm{~cm}^{2}\right)$ film was degreased in acetone and then annealed at $450{ }^{\circ} \mathrm{C}$ for $5 \mathrm{~h}$ in $\mathrm{Ar}$ atmosphere. The sample was electropolished in a $1: 4$ (volume ratio) solution of perchloric acid-ethanol at $25 \mathrm{~V}, 10^{\circ} \mathrm{C}$. (Caution: the combination of perchloric acid and alcohols is a known explosion hazard - extreme caution, even with cooling, should be exercised.) The $\mathrm{Al}$ film was placed in $0.3 \mathrm{M}$ oxalic acid at $17^{\circ} \mathrm{C}$ and anodized at $40 \mathrm{~V}$ for $12 \mathrm{~h}$. Subsequently, this initial oxide layer was completely etched away at $80^{\circ} \mathrm{C}$ in a solution of $1.8 \mathrm{wt} \%$ chromic acid $-5 \mathrm{wt} \%$ phosphoric acid. A second anodization was then carried out in $0.3 \mathrm{M}$ oxalic acid at $17{ }^{\circ} \mathrm{C}$ and $40 \mathrm{~V}$ for $2 \mathrm{~h}$. Two carbon bars were employed as a counter electrode and a Kepco power supply (KLP 300-8-1200) was used to control current and voltage.

Combined mild-hard anodic aluminium oxide (Mi-Ha AAO) templates were synthesized by a three-step anodization procedure. Initially the synthesis follows the anodizing procedures as described above on conventional Mi-AAO through the secondstep, then an additional hard anodization step at $5{ }^{\circ} \mathrm{C}$ was carried out at $100 \mathrm{~V}$ for $30 \mathrm{~min}$. To obtain this potential, the voltage was slowly increased from $40 \mathrm{~V}$ to $100 \mathrm{~V}$ over several minutes during which time the current density dramatically increased to $160 \mathrm{~mA} \mathrm{~cm}^{-2}$. The current density then dropped over the next several minutes to around $20 \mathrm{~mA} \mathrm{~cm}^{-2}$.

After the second (Mi-AAO) or third anodization ( $\mathrm{Mi}-\mathrm{Ha}$ AAO) steps, templates were detached from the Al film by an electrochemical treatment in $1: 1$ mixture solution of perchloric acid-ethanol at $100 \mathrm{~V}$ for $10 \mathrm{~s}$ at $10^{\circ} \mathrm{C}$. To completely remove the barrier layers, samples were then immersed in a $5 \mathrm{wt} \%$ phosphoric acid solution for several minutes. The samples were rinsed with distilled water and acetone. The mild membrane (Mi-AAO) had $70 \mathrm{~nm}$ pores and the mild-hard membrane (Mi-Ha AAO) had $70 \mathrm{~nm}$ pores on the mild side and $110 \mathrm{~nm}$ pores on the hard side. Typically Mi-Ha AAO membranes ( $c a .50 \mu \mathrm{m}$ thick) contained $15 \mu \mathrm{m}$ mild regions and $35 \mu \mathrm{m}$ hard regions. Fig. 1 highlights the complete fabrication process for both Mi-AAO and $\mathrm{Mi}-\mathrm{Ha}$ AAO templates.

\section{Synthesis of $\mathrm{Ni}$ and $\mathrm{Co}$ nanowires}

$\mathrm{Ni}$ and Co nanowires were grown in the pores of AAO templates by an electrodeposition method. The AAO membranes were formed into electrodes by first sputtering a thin layer of $\mathrm{Ag}$ film onto one side of the template. For the Mi-Ha AAO, wires could be grown on either the hard or mild side of the template. $\mathrm{Cu}$ tape (3M) was attached to the Ag coating and then that side of the template was sealed with $3 \mathrm{M}$ scotch tape. An alligator clip was used to make contact to the $\mathrm{Cu}$ tape. Ni plating solution (Nickel sulfamate-RTU) was obtained from Technics Inc. and Co plating solution was prepared with $240 \mathrm{~g} \mathrm{~L}^{-1}$ cobalt sulfate heptahydrate $\left(99 \% \mathrm{CoSO}_{4} \cdot 7 \mathrm{H}_{2} \mathrm{O}\right.$, Sigma) and $40 \mathrm{~g} \mathrm{~L}^{-1}$ boric acid (99.5\% $\mathrm{H}_{3} \mathrm{BO}_{4}$, Alfa Aesar). Metal nanowires were prepared at room temperature by a constant current method at $-0.5 \mathrm{~mA}$ over several minutes on a Princeton Applied Research VMP2 with a $\mathrm{Pt}$ wire counter electrode. In those instances where removal of the template was desired, the sample was treated with a $0.1 \mathrm{M} \mathrm{NaOH}$ solution for $1 \mathrm{~h}$.

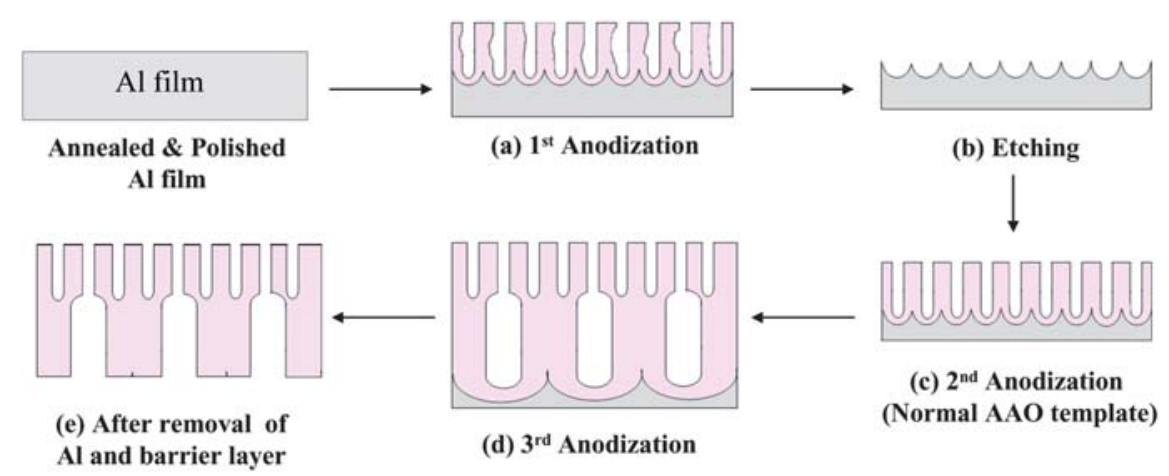

Fig. 1 Schematic diagram of fabrication procedures for AAO templates. (a) First anodization of polished $\mathrm{Al}$ film at $40 \mathrm{~V}$ and $17^{\circ} \mathrm{C}$, (b) etching of oxide layer, (c) second anodization at $40 \mathrm{~V}$ and $17^{\circ} \mathrm{C}$ (Mi-AAO), (d) third anodization at $100 \mathrm{~V}$ and $5{ }^{\circ} \mathrm{C}$ (Mi-Ha AAO), and (e) after removal of barrier layer and $\mathrm{Al}$ film. 


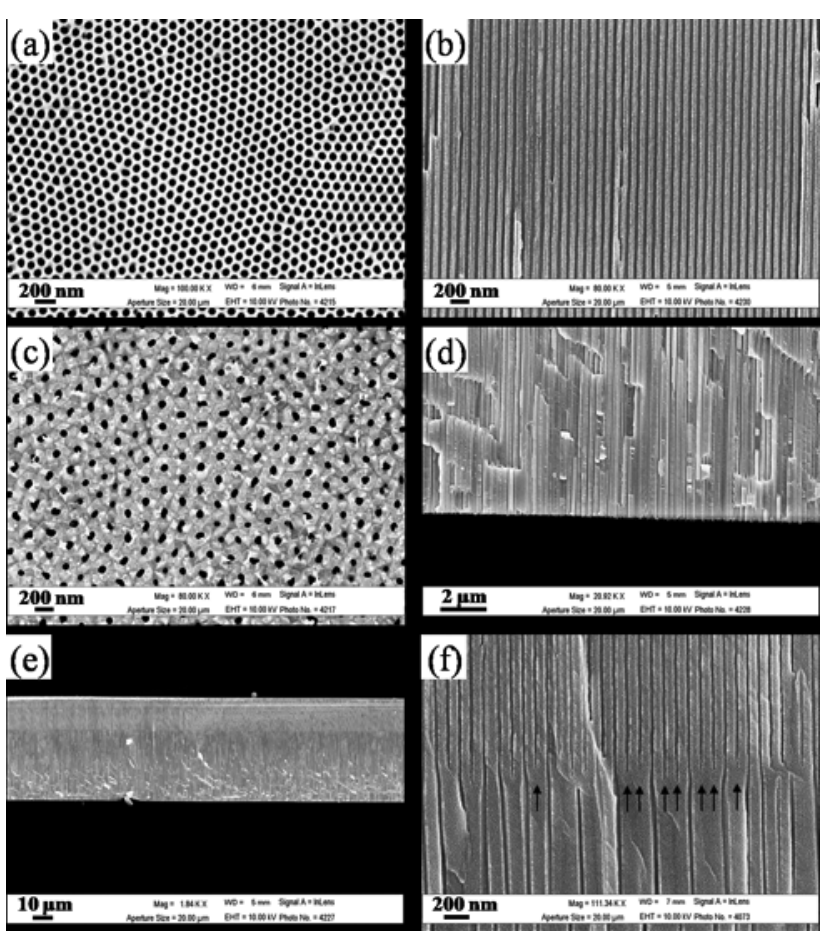

Fig. 2 FESEM images of Mi-Ha AAO template. Top surface (a) and cross-section view (b) of mild side. Top surface (c) and cross-section view (d) of hard side. (e) Image shows cross-section view of the boundary of mild (top) and hard side (bottom). (f) Higher magnification view of boundary region of mild (top) and hard side (bottom); black arrows highlight some selected pores that have been terminated in the hard anodization step.

\section{Characterization}

Field-emission scanning electron microscopy (FESEM) was carried out on a LEO $1530 \mathrm{VP}$ and transmission electron microscopy (TEM) was performed on a JEOL 2010 electron microscope with a $200 \mathrm{kV}$ acceleration voltage. A Philips X-pert PW 3040 MPD X-ray powder diffractometer with $\mathrm{Cu} \mathrm{K} \alpha$ radiation was used to collect X-ray diffraction (XRD) data on the nanowire-membrane composites; the sample was mounted with the wires oriented perpendicular to the sample holder. The static

Table 1 Structural properties of normal Mi-AAO and Mi-Ha AAO template

\begin{tabular}{|c|c|c|c|}
\hline \multirow[b]{3}{*}{ Condition } & \multicolumn{3}{|l|}{ Template } \\
\hline & \multirow[b]{2}{*}{ Mi-AAO } & \multicolumn{2}{|l|}{ Mi-Ha AAO } \\
\hline & & Mild side & Hard side \\
\hline Temperature $/{ }^{\circ} \mathrm{C}$ & 17 & 17 & 5 \\
\hline Voltage/V & 40 & 40 & 100 \\
\hline Film growth rate $/ \mu \mathrm{m} \mathrm{h}^{-1}$ & 7.5 (linear) & 7.5 (linear) & 55 (nonlinear) \\
\hline Pore diameter $/ \mathrm{nm}$ & $70 \pm 3$ & $70 \pm 3$ & $110 \pm 10$ \\
\hline $\begin{array}{l}\text { Barrier layer } \\
\text { thickness/nm }\end{array}$ & 50 & None & 130 \\
\hline $\begin{array}{l}\text { Interpore distance } \\
\qquad\left(D_{\text {int }}\right) / \mathrm{nm}\end{array}$ & 100 & $200-300$ & $265 \pm 10$ \\
\hline Pore density ${ }^{a} /$ pore $\mathrm{cm}^{-2}$ & $1.15 \times 10^{10}$ & 1.28 to $2.88 \times 10^{9}$ & $1.64 \times 10^{9}$ \\
\hline${ }^{a}$ From ref. 8, pore densit & $\mathrm{y}:\left(2 / \sqrt{3} D_{\mathrm{int}}{ }^{2}\right)$ & 2) $\times 10^{14} \mathrm{~cm}^{-2}$ & \\
\hline
\end{tabular}

magnetic behavior of the nanowire samples was studied with a vibrating sample magnetometer (VSM), Lakeshore 7300 Series; room temperature hysteresis data were collected on the nanowire-membrane composites with the wire oriented both parallel $\left(0^{\circ}\right)$ and perpendicular $\left(90^{\circ}\right)$ to the magnetic field.

\section{Results}

AAO templates with $70 \mathrm{~nm}$ pore diameter and straight pore channels are readily synthesized under mild conditions. These membranes (Mi-AAO) have an interpore distance of about $100 \mathrm{~nm}$ and a pore density of $c a .1 .2 \times 10^{10}$ pores $\mathrm{cm}^{-2}$. In contrast, hard anodization produces membranes with larger interpore distances, $265 \mathrm{~nm}$, and lower pore densities, $c a$. $1.6 \times$ $10^{9}$ pores $\mathrm{cm}^{-2}$. When used sequentially, the combination of both mild and hard anodization produces membranes (Mi-Ha AAO) with a distinct structure. While the mild (Fig. 2a and b) and hard (Fig. 2c and d) sides are comparable to that expected for the individual membranes (Table 1), the structure at the interface and the impact of this on the active pore structure are significant. Fig. 2e and $f$ show the low and high magnification images of the pore structure at the interface. In the transition from the mild region to the hard region approximately half of the channels remain continuous throughout the membrane while other pores initiated on the mild side terminate at the mild-hard interface. This effectively increases the distance between active pores on the mild side by as much as 3 times and in turn, decreases the pore density to values similar to that of the hard anodized portion of the membrane (Table 1). Similar structures have been reported recently by Shuoshuo and coworkers. ${ }^{4}$

The Mi-Ha AAO can be employed as a membrane for the fabrication of magnetic nanowire arrays. Wires were grown either in the hard or mild side of these membranes. Fig. 3 shows cross-sectional images of nickel nanowires grown in various parts of the Mi-Ha membrane. In the hard side of the membrane (Fig. 3a), $110 \mathrm{~nm}$ diameter wires are readily obtained within all

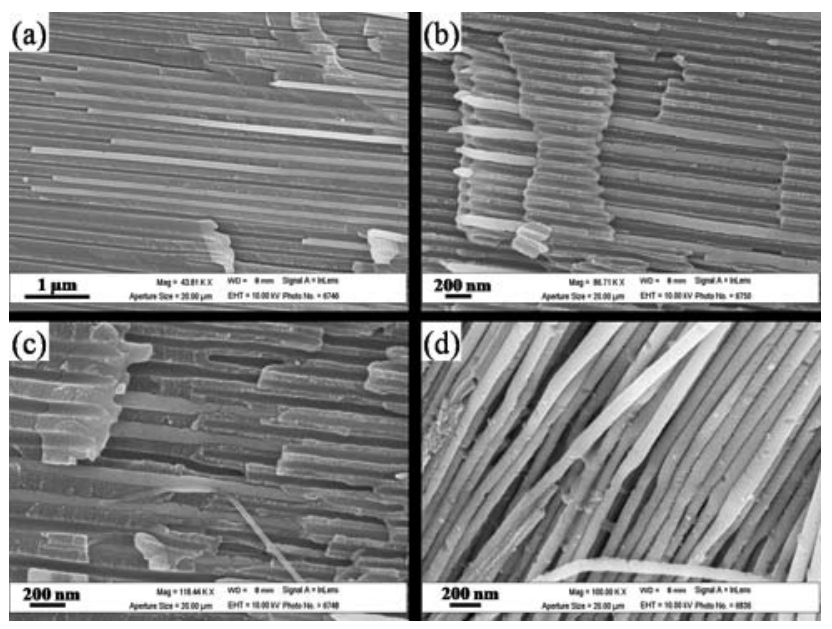

Fig. 3 FESEM images of $\mathrm{Ni}$ nanowires synthesized in Mi-Ha AAO template. (a) $110 \mathrm{~nm}$ diameter wires grown on the hard side of the template. (b) $70 \mathrm{~nm}$ nanowires grown on mild side; growth of wires in alternating pores is clearly shown. Nanowires grown across mild-hard interface, larger diameter portion of wire from hard side of template: (c) wires still in template and (d) wires shown after removal of template. 
(a)
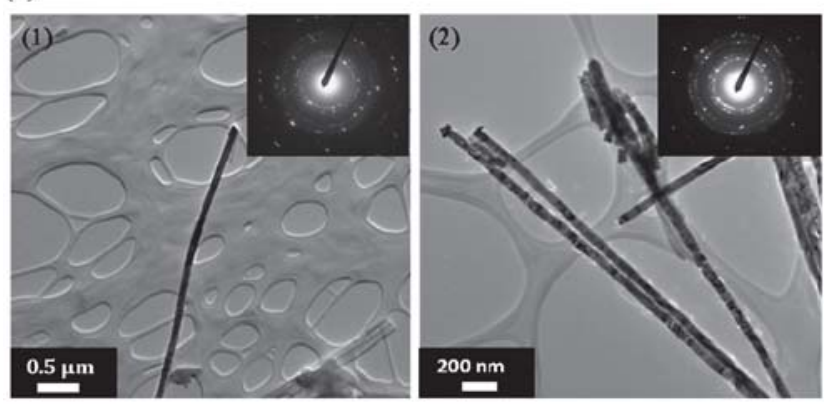

(b)

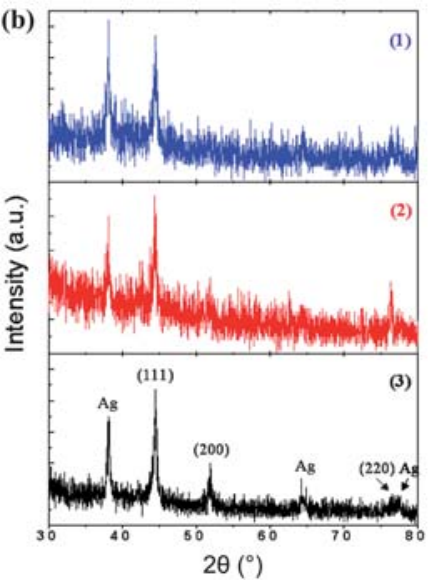

Fig. 4 TEM image and diffraction data for Ni nanowires. (a) TEM image of dispersed Ni nanowires synthesized in mild side of Mi-Ha (a1) and Mi-AAO (a2). Inset shows SAED pattern, indicating polycrystalline structure. (b) XRD data for Ni nanowires in AAO templates: (b1) mild side and (b2) hard side of Mi-Ha AAO, (b3) normal Mi-AAO. (Ag from conducting film on bottom of AAO template.)

available pores. Wires fabricated in the mild side of the AAO template, however, only grow in selected pores. Fig. 3b shows several nickel wires occupying alternating channels. In Fig. 3c, long wires $(22 \mu \mathrm{m})$ that were grown across the mild-hard interface, exhibit a variation in diameter as expected in this region of the membrane. This is more obvious after removal of the template (Fig. 3d). TEM images of dispersed nickel wires synthesized in the mild side of $\mathrm{Mi}-\mathrm{Ha}$ and $\mathrm{Mi}-\mathrm{AAO}$ are presented in Fig. 4a1 and 4a2; selected area electron diffraction (SAED, inset) shows both sets of wires to be polycrystalline though highly crystalline in nature (distinct single crystalline regions are found along the length of the wire, ESI $\dagger$, Fig. S1). Also, XRD data in Fig. 4b reveal that the Ni nanowires in Mi-Ha AAO have an fcc structure with a highly oriented growth in the (111) direction (Ag peaks are from conducting metal film used in electrodeposition). For the cobalt nanowires synthesized in $\mathrm{Mi}-\mathrm{Ha}$ AAO, TEM and SAED results in Fig. 5a1 and 5a2, and $\mathrm{S} 2 \dagger$ present evidence for polycrystalline nanowires with highly crystalline regions. XRD (Fig. 5b1 and 5b2) of these wires shows the (101) and (100) directions of the hep structure. In contrast, Co nanowires grown in the Mi-AAO template exhibit a strong (100) orientation (Fig. 5b3).

Magnetization studies as a function of field were carried out on $\mathrm{Ni}$ and $\mathrm{Co}$ nanowires grown on the mild and hard sides of Mi-Ha AAO template as well as those grown in the standard Mi-AAO (Fig. 6 and 7 and Table 2). Hysteresis loops were (a)
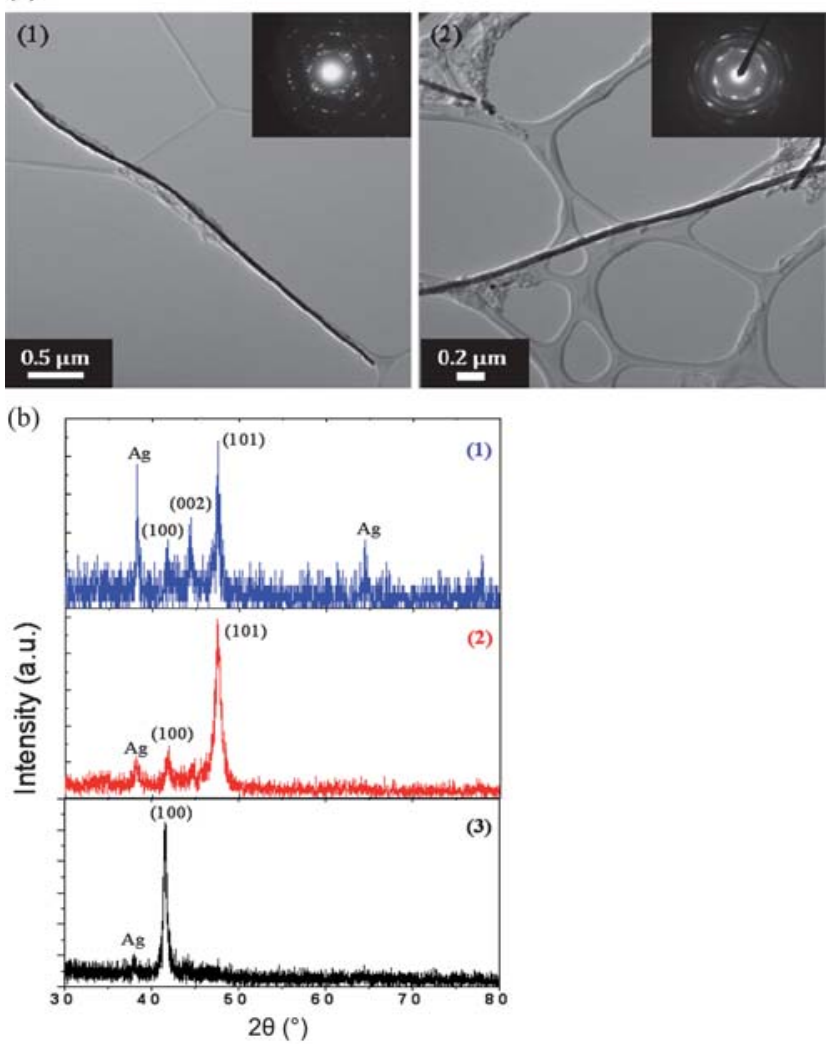

Fig. 5 TEM image and diffraction data for Co nanowires. (a) TEM image of dispersed Co nanowires synthesized in mild side of $\mathrm{Mi}-\mathrm{Ha}$ (a1) and Mi-AAO (a2). Inset shows SAED pattern, indicating polycrystalline structure. (b) XRD data for Co nanowires in AAO templates: (1) mild side and (2) hard side of Mi-Ha AAO, and (3) normal Mi-AAO. (Ag from conducting film on bottom of AAO template.)

obtained at room temperature for fields both parallel $\left(0^{\circ}\right)$ and perpendicular $\left(90^{\circ}\right)$ to the wires. When the field is applied $0^{\circ}$, hysteresis loops show a higher coercivity in all systems. Magnetization of $3.3 \mu \mathrm{m}$ and $11 \mu \mathrm{m}$ nickel nanowires from the mild-side of a Mi-Ha AAO template is shown in Fig. 6a and b, respectively. As expected, ${ }^{21,22}$ the coercivity increases with increasing aspect ratio where the $3.4 \mu \mathrm{m}$ wires exhibit a coercivity of $640 \mathrm{Oe}$ and the $11 \mu \mathrm{m}$ wires, $720 \mathrm{Oe}$. Also, the squareness of hysteresis loops $\left(M_{\mathrm{r}} / M_{\mathrm{s}}\right.$, defined as the ratio of the magnetic remanence $\left(M_{\mathrm{r}}\right)$ to the saturation magnetization $\left(M_{\mathrm{s}}\right)$ ) is almost unity at about 0.99 . For $3.4 \mu \mathrm{m}$ nanowires grown in a normal Mi-AAO template, the hysteresis loop is shown in Fig. 6c; here there is an increase in the coercivity to 878 Oe but a reduction in the squareness to about 0.82 . Fig. $6 \mathrm{~d}$ presents hysteresis data on $3.8 \mu \mathrm{m} \mathrm{Ni}$ nanowires synthesized on the hard side of $\mathrm{Mi}-\mathrm{Ha}$ AAO template. These wires have a similar interwire distance to those in Fig. 6a and b, but with a larger diameter of $110 \mathrm{~nm}$. Here the coercivity and squareness are much less, 398 Oe and 0.39, respectively. It is well-known that increasing the relative diameter can decrease the squareness and coercivity of nanowires, ${ }^{\mathbf{1 2}}$ though nonuniformity in wire diameters may also contribute to this behavior.

Fig. 7 and Table 2 present the magnetization data for the series of cobalt nanowires. Like the nickel wires, the squareness $(0.90)$ 

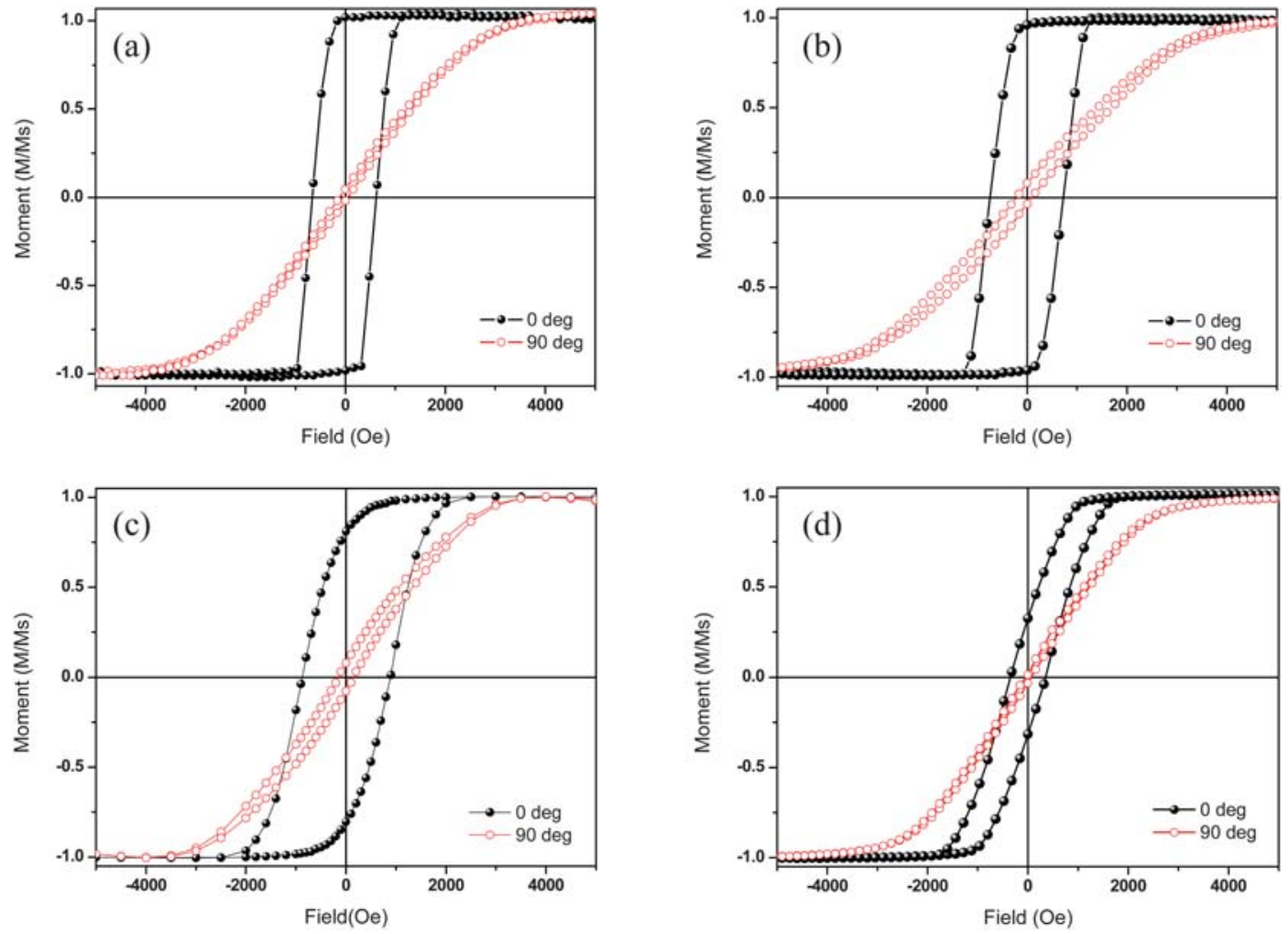

Fig. 6 Hysteresis loops of Ni nanowires: wires grown on mild side of Mi-Ha AAO (70 nm diameters, 200-300 nm interwire distances) with lengths of (a) $3.3 \mu \mathrm{m}$ and (b) $11 \mu \mathrm{m}$; (c) wires in Mi-AAO (70 nm diameters, $100 \mathrm{~nm}$ interwire distances) with $3.4 \mu \mathrm{m}$ length; (d) wires grown in hard side of Mi-Ha AAO (110 nm diameters, $265 \mathrm{~nm}$ interwire distances) with $3.8 \mu \mathrm{m}$ length.
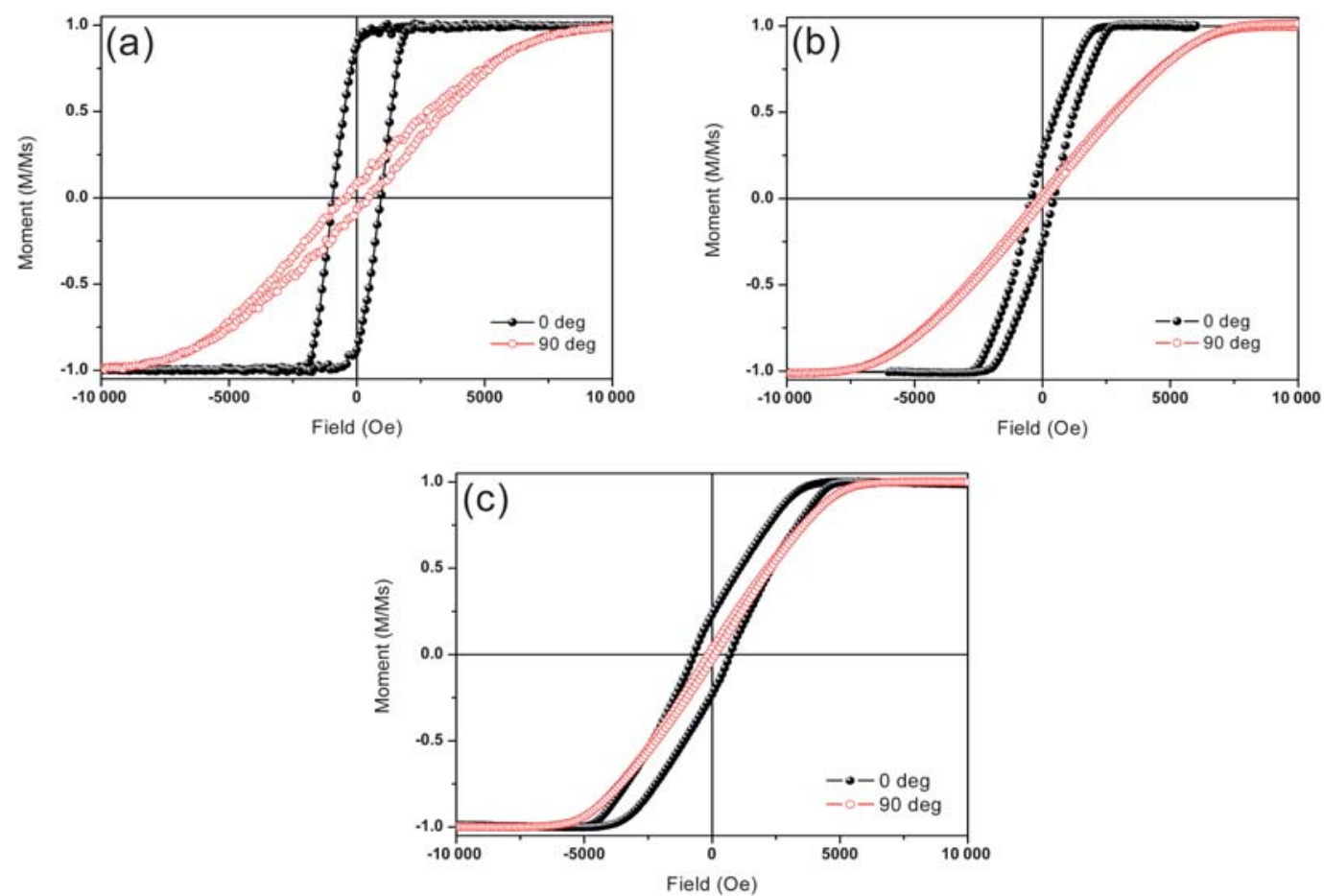

Fig. 7 Hysteresis loops of Co nanowires: (a) wires grown in mild side of Mi-Ha AAO (70 nm diameters, 200-300 nm interwire distances) with $4.5 \mu$ m length; (b) wires grown in Mi-AAO (70 nm diameters, $100 \mathrm{~nm}$ interwire distances) with $4.7 \mu \mathrm{m}$ length: (c) wires grown in hard side of Mi-Ha AAO (110 $\mathrm{nm}$ diameters, $265 \mathrm{~nm}$ interwire distances) with $4.8 \mu \mathrm{m}$ length. 
Table 2 Summary of magnetic data for nickel and cobalt nanowire composite arrays

\begin{tabular}{|c|c|c|c|c|c|c|}
\hline Template & Diameter/nm & Length/ $\mu \mathrm{m}$ & Interpore distance/nm & Angle $/^{\circ}$ & Coercivity/Oe & Squareness $\left(M_{\mathrm{r}} / M_{\mathrm{s}}\right)$ \\
\hline \multicolumn{7}{|l|}{ Nickel } \\
\hline Mild & 70 & 3.4 & 100 & 0 & 878 & 0.82 \\
\hline \multirow[t]{2}{*}{ Mi-Ha (mild side) } & \multirow[t]{2}{*}{70} & \multirow[t]{2}{*}{3.3} & \multirow[t]{2}{*}{$200-300$} & 0 & 640 & 0.99 \\
\hline & & & & 90 & 80 & 0.03 \\
\hline \multirow[t]{2}{*}{ Mi-Ha (mild side) } & \multirow[t]{2}{*}{70} & \multirow[t]{2}{*}{11} & \multirow[t]{2}{*}{$200-300$} & 0 & 720 & 0.99 \\
\hline & & & & 90 & 156 & 0.06 \\
\hline \multicolumn{7}{|l|}{ Cobalt } \\
\hline \multirow[t]{2}{*}{ Mild } & \multirow[t]{2}{*}{70} & \multirow[t]{2}{*}{4.7} & \multirow[t]{2}{*}{100} & 0 & 750 & 0.23 \\
\hline & & & & 90 & 150 & 0.03 \\
\hline \multirow{2}{*}{ Mi-Ha (mild side) } & \multirow[t]{2}{*}{70} & \multirow[t]{2}{*}{4.5} & \multirow[t]{2}{*}{$200-300$} & 0 & 950 & 0.90 \\
\hline & & & & 90 & 400 & 0.08 \\
\hline Mi-Ha (hard side) & 110 & 4.8 & 265 & 0 & 440 & 0.25 \\
\hline
\end{tabular}

for the wires grown on the mild side of the Mi-Ha AAO template is greater than either of those from the normal template $(0.23)$ or the hard side of the Mi-Ha AAO template (0.25). Unlike the nickel wires, however, the coercivity for the cobalt wires grown on the mild side of the Mi-Ha AAO (950 Oe) is larger than the normal wires $(750 \mathrm{Oe})$.

\section{Discussion}

When considering magnetic interactions between adjacent magnetic nanowires, the ability to control the distance between wires by varying the pore structure of a template is of interest because it allows one to investigate the impact on wire-wire interactions. Some researchers have suggested that magnetic nanowire arrays could be used as tunable microwave filters. ${ }^{18,19,21}$ For such applications, a better understanding of wire-wire interactions is needed to optimize absorption properties and varying the pore structure in AAO templates is one avenue to probe this behavior.

We have prepared a series of templates with two different pore structures so as to study the interactions between adjacent magnetic nanowires. The interpore distance of normal Mi-AAO template is about $100 \mathrm{~nm}$. In the hard anodization, the interpore distance is about $265 \mathrm{~nm}$. The stepwise application of mild and hard anodization initially starts with an interpore distance of about $100 \mathrm{~nm}$, but once the hard anodization step is initialized the production of larger pores results in a termination of many of the mild side pores (Fig. 2f). This produces a membrane where, though the interpore distance appears the same on the mild side (Fig. 2a), the distance between continuous open pores is actually approximately 200-300 nm (Fig. 2f). Terminated pore channels were obtained when the voltage was increased. The electric field becomes redistributed between the barrier layer and metal surface to reduce stress. The field is concentrated on selected pore channels so as to produce a thinner barrier layer relative to neighboring pores; the thinner barrier layer supports continued development of the selected pores while the thicker layers on neighboring pores curtail the electrolyte diffusion needed for sustained growth, so these pores terminate.

The crystalline nature and orientation of nanowires grown in porous templates are highly influenced by electrodeposition conditions including $\mathrm{pH}$, current, frequency, and temperature. ${ }^{11,12,23}$ While we used the same deposition conditions in the growth of sets of nanowires, variation was still observed. In the cobalt system, orientation of wires grown in the Mi-AAO differed from those in $\mathrm{Mi}-\mathrm{Ha} \mathrm{AAO}$. Recent reports have described that the templates themselves ${ }^{24,25}$ can have an important impact, where it is believed pore wall surface morphology as well as species incorporated into the pore wall during anodization in different acid solutions are important. In our studies, the important difference between the $\mathrm{Mi}-\mathrm{Ha} \mathrm{AAO}$ and $\mathrm{Mi}-\mathrm{AAO}$ templates arises from the anodization conditions used in their fabrication. In the hard anodization step, which immediately follows the mild anodization step, the mild side of $\mathrm{Mi}-\mathrm{Ha} \mathrm{AAO}$ template experiences much more extreme conditions due to the extensive local heating accompanying this process. These elevated temperatures may influence the membrane wall surface morphology and composition, even at the mild end of the membrane, subsequently impacting the nucleation and growth orientation of the magnetic wires. Further influence may come from the growth of the wires - the $\mathrm{Mi}-\mathrm{Ha} \mathrm{AAO}$ template is thicker with a smaller pore density. Since wires are grown in Mi-AAO and Mi-Ha AAO under the same conditions, those grown in $\mathrm{Mi}-\mathrm{Ha} \mathrm{AAO}$ grow at a faster rate and this might also influence the relative magnetic properties of the sets of wires.

Magnetization of nickel and cobalt nanowires is influenced by magnetocrystalline and shape anisotropy, as well as dipolar coupling between adjacent wires. The ratio of nanowire diameter to interwire distance is an important factor influencing the coercivity and squareness of hysteresis loops. ${ }^{26}$ In general, when the ratio is decreased, coercivity and squareness increase due to the decreasing dipolar coupling between nanostructures. Cheng et al., ${ }^{17}$ using the micromagnetic simulations, investigated changes in magnetostatic interactions on varying the number, size and distance between interacting nanowires. They found that the coercivity and squareness decreased with increasing number and diameter of neighboring wires and increased with increasing interwire distance. In our study, when the field is applied $0^{\circ}$ (parallel to the wires), hysteresis loops show a higher coercivity in all systems as shown in Fig. 6 and 7 and Table 2. This result is consistent with the easy axis of magnetization being parallel to the wire. The squareness of the hysteresis loops for $\mathrm{Ni}$ 
(Fig. 6a) and Co (Fig. 7a) nanowires synthesized in the mild side of $\mathrm{Mi}-\mathrm{Ha} \mathrm{AAO}$ is larger compared to that in the normal Mi$\mathrm{AAO}$ or hard side of $\mathrm{Mi}-\mathrm{Ha} \mathrm{AAO}$. The lower squareness in the Mi-AAO relates to greater dipole interactions between nanowires when the wires are close together. It is evident that larger interwire distances minimize such dipole interactions. In the case of the cobalt system, the coercivity of Co nanowires is greater for the Mi-Ha AAO (Fig. 7a) versus that of the normal Mi-AAO (Fig. 7c). In contrast, the coercivities of $\mathrm{Ni}$ nanowires in $\mathrm{Mi}-\mathrm{Ha}$ AAO (Fig. 6a) decreased compared to Mi-AAO (Fig. 6c). Recently $\mathrm{we}^{20}$ and others ${ }^{25}$ observed similar variations in coercivity in $\mathrm{Fe}$ nanowires as a function of interpore distance. Clearly the coercivity of nanowires is not only strictly dependent on the dipole interactions, but also magnetocrystalline and shape anisotropy play an important role in these properties. Detailed magnetic studies are warranted to better understand this behavior. First-order reversal curve (FORC) diagrams have been recently applied to map coercive field distributions and wire-wire interactions in nanowire arrays..$^{27,28}$ Such FORC studies as a function of interwire distance would better illuminate the behavior as a function of interpore distances - such studies are currently underway and will be reported elsewhere. ${ }^{29}$

\section{Conclusions}

Mi-Ha AAO templates with selectively opened pore channels were produced by sequential application of both mild and hard anodizing processes. An interpore distance of $\mathrm{Mi}-\mathrm{Ha} \mathrm{AAO}$ was increased as much as 3 times compared to conventional Mi-AAO and the pore size was also modulated by the combination of mild and hard anodizations. Fabrication of AAO templates with varying interpore distance allows one to probe the magnetic interactions of adjacent nanowires. While an improvement in squareness can readily be seen on separation of both nickel and cobalt nanowires, the influence of this separation on coercivities is apparently more complex. Further investigation is needed to better understand the influence of wire-wire interactions on coercivity.

\section{Acknowledgements}

Support by the National Science Foundation through the NIRT program (NSF-0403673) is gratefully acknowledged. Special thanks to Prof. L. Spinu and Dr. B. Cao for helpful discussions.

\section{References}

1 H. Masuda and K. Fukuda, Science, 1995, 268, 1466

2 Y. Li, Z. Y. Ling, S. S. Chen and J. C. Wang, Nanotechnology, 2008, 19, 225604.

3 T. Gao, G. Meng, J. Zhang, S. Sun and L. Zhang, Appl. Phys. A: Mater. Sci. Process., 2002, 74, 403.

4 C. Shuoshuo, L. Zhiyuan, H. Xing and L. Yi, J. Mater. Chem., 2009, 19, 5717.

5 S. Zhao, K. Chan, A. Yelon and T. Veres, Adv. Mater., 2007, 19, 3004.

6 H. Masuda, H. Asoh, M. Watanabe, K. Nishio, M. Nakao and T. Tamamura, Adv. Mater., 2001, 13, 189.

7 Y. B. Li, M. J. Zhang and L. Ma, Appl. Phys. Lett., 2007, 91, 073109.

8 W. Lee, R. Ji, U. Gösele and K. Nielsch, Nat. Mater., 2006, 5, 741.

9 W. Lee, R. Scholz and U. Gösele, Nano Lett., 2008, 8, 2155.

10 S. Yang, H. Zhu, D. Yu, Z. Jin, S. Tang and Y. Du, J. Magn. Magn. Mater., 2000, 222, 97.

11 X. Huang, L. Li, X. Luo, X. Zhu and G. Li, J. Phys. Chem. C, 2008, 112, 1468 .

12 H. Pan, B. Liu, J. Yi, C. Poh, S. Lim, J. Ding, Y. Feng, C. H. A. Huan and J. Lin, J. Phys. Chem. B, 2005, 109, 3094.

13 F. M. F. Rhen, E. Backen and J. M. D. Coey, J. Appl. Phys., 2005, 97, 113908.

14 Y. Dahmane, L. Cagnon, J. Voiron, S. Pairis, M. Bacia, L. Ortega, N. Benbrahim and A. Kadri, J. Phys. D: Appl. Phys., 2006, 39, 4523.

15 T. Wang, Y. Wang, F. Li, C. Xu and D. Zhou, J. Phys.: Condens. Matter, 2006, 18, 10545.

16 X. Kou, X. Fan, H. Zhu and J. Q. Xiao, Appl. Phys. Lett., 2009, 94, 112509.

17 D.-L. Sun, J.-H. Gao, X.-Q. Zhang, Q.-F. Zhan, W. He, Y. Sun and Z.-H. Cheng, J. Magn. Magn. Mater., 2009, 321, 2737.

18 M. Darques, J. Spiegel, J. De la Torre Medina, I. Huynen and L. Piraux, J. Magn. Magn. Mater., 2009, 321, 2055.

19 A. Encinas-Oropesa, M. Demand, L. Piraux, I. Huynen and U. Ebels, Phys. Rev. B: Condens. Matter, 2001, 63, 104415.

20 J.-H. Lim, W.-S. Chae, H.-O. Lee, L. Malkinski, S.-G. Min, J. B. Wiley, J.-H. Jun, S.-K. Ham and J.-S. Jung, J. Appl. Phys., 2010, 107, 09A334.

21 O. C. Trusca, D. Cimpoesu, J.-H. Lim, X. Zhang, J. B. Wiley, A. Diaconu, I. Dumitru, A. Stancu and L. Spinu, IEEE Trans. Magn., 2008, 44, 2730.

22 S. L. Oh, Y. R. Kim, L. Malkinski, A. Vovk, S. L. Whittenburg, E. M. Kim and J. S. Jung, J. Magn. Magn. Mater., 2007, 310, e827.

23 J. Zhang, G. A. Jones, T. H. Shen, S. E. Donnelly and G. Li, J. Appl. Phys., 2007, 101, 054310.

24 N. J. Gerein and J. A. Haber, J. Phys. Chem. B, 2005, 109, 17372.

25 J. M. Baik, M. Schierhorn and M. Moskovits, J. Phys. Chem. C, 2008, 112, 2252.

26 M. Vázquez, M. Hernández-Vélez, K. Pirota, A. Asenjo, D. Navas, J. Velázquez, P. Vargas and C. Ramos, Eur. Phys. J. B, 2004, 40, 489.

27 L. Spinu, A. Stancu, C. Radu, F. Li and J. B. Wiley, IEEE Trans. Magn., 2004, 40, 2116.

28 M. Ciureanu, F. Beron, P. Ciureanu, R. W. Cochrane, D. Menard, A. Sklyuyev and A. Yelon, J. Nanosci. Nanotechnol., 2008, 8, 5725.

29 A. Rotaru, J.-H. Lim, L. Spinu and J. B. Wiley, unpublished work. 